\title{
Strategies for regenerating injured axons after spinal cord injury - insights from brain development
}

\author{
Masaki Ueno \\ Toshihide Yamashita \\ Department of Molecular \\ Neuroscience, Graduate School \\ of Medicine, Osaka University, 2-2 \\ Yamadaoka, Suita-shi, Osaka 565-087I, \\ Japan
}

\begin{abstract}
Axonal regeneration does not occur easily after an adult central nervous system (CNS) injury. Various attempts have partially succeeded in promoting axonal regeneration after the spinal cord injury (SCI). Interestingly, several recent therapeutic concepts have emerged from or been tightly linked to the researches on brain development. In a developing brain, remarkable and dynamic axonal elongation and sprouting occur even after the injury; this finding is essential to the development of a therapy for SCI. In this review, we overview the revealed mechanism of axonal tract formation and plasticity in the developing brain and compare the differences between a developing brain and a lesion site in an adult brain. One of the differences is that mature glial cells participate in the repair process in the case of adult injuries. Interestingly, these cells express inhibitory molecules that impede axonal regeneration such as myelin-associated proteins and the repulsive guidance molecules found originally in the developing brain for navigating axons to specific routes. Some reports have clearly elucidated that any treatment designed to suppress these inhibitory cues is beneficial for promoting regeneration and plasticity after an injury. Thus, understanding the developmental process will provide us with an important clue for designing therapeutic strategies for recovery from SCI.
\end{abstract}

Keywords: development, regeneration, spinal cord injury

\section{Introduction}

Axonal regeneration is a fundamental step in the process of recovering from spinal cord injury (SCI). However, the axons in the adult central nervous system (CNS) cannot regenerate easily, which primarily causes the lack of adequate restorative therapy for the SCI so far. Several attempts have been made to promote regeneration, and some advances have been obtained. Importantly, these attempts appear to be the applications of certain extensively revealed mechanisms of brain development. Although the axons cannot regenerate easily in an adult brain, in the developing brain, differentiating neurons elongate the axons easily to very distal areas; this information is of utmost importance and is required to be considered post SCI. What is the difference between the ability of elongating the axons in the adult and developing brain? Understanding the mechanism of tremendous axonal elongation and navigation during development and the differences between the environments of adult and developing CNS has provided us with important clues for succeeding in regenerating axons after brain injuries. Although several allusions for the therapy have also been brought by the comparison between the peripheral nervous system (PNS) and the CNS because axons can regenerate in the former system but not in the latter, in this review, we will focus on and compare the differences between the adult and developing brain. We have briefly summarized the differences discussed in this review in Figure 1C. From this view, we can consider how the recent concepts and strategies for regenerating axons in the adult CNS have 
emerged and can be developed. Although several excellent reviews have yet described the importance of the relation of regenerative therapy with the developmental mechanisms (Schwab and Bartholdi 1996; Harel and Strittmatter 2006), we will overview the whole aspects of its relations as much as possible with recent reports, and will emphasize that collaboration with developmental and clinical neuroscience is more needed.

\section{Axonal regeneration in the developing brain}

Many earlier reports indicate that the axons in the early postnatal spinal cord can regenerate more easily after an injury compared to those in an adult (Figure 1: Berstein and Stelzner 1983; Bates and Stelzner 1993; Firkins et al 1993). This finding provides two main important suggestions. First, early brain tissue possesses favorable factors and environment for axonal growth, and the second, younger neurons themselves have a greater capacity for outgrowth than adult neurons. The first suggestion is a well-accepted concept, and many inhibitory factors in the adult brain have been identified up till now. We have reviewed these factors in the coming chapters; however, the important point is that understanding the favorable environment for axonal growth in the developing brain may generate a new approach in the designing of a therapy for SCI. Indeed, in many classical experiments, embryonic spinal cord was transplanted in the lesion site of the postnatal and adult spinal cord (Bregman et al 1989, 1993; Iwashita et al 1994). In the early postnatal case, injured axons demonstrated immense regeneration passing through the transplanted embryonic tissue. In the adult case, axons could regenerate slightly but not dramatically. This also supports the abovementioned two suggestions, that early tissue is favorable for axonal growth, and younger

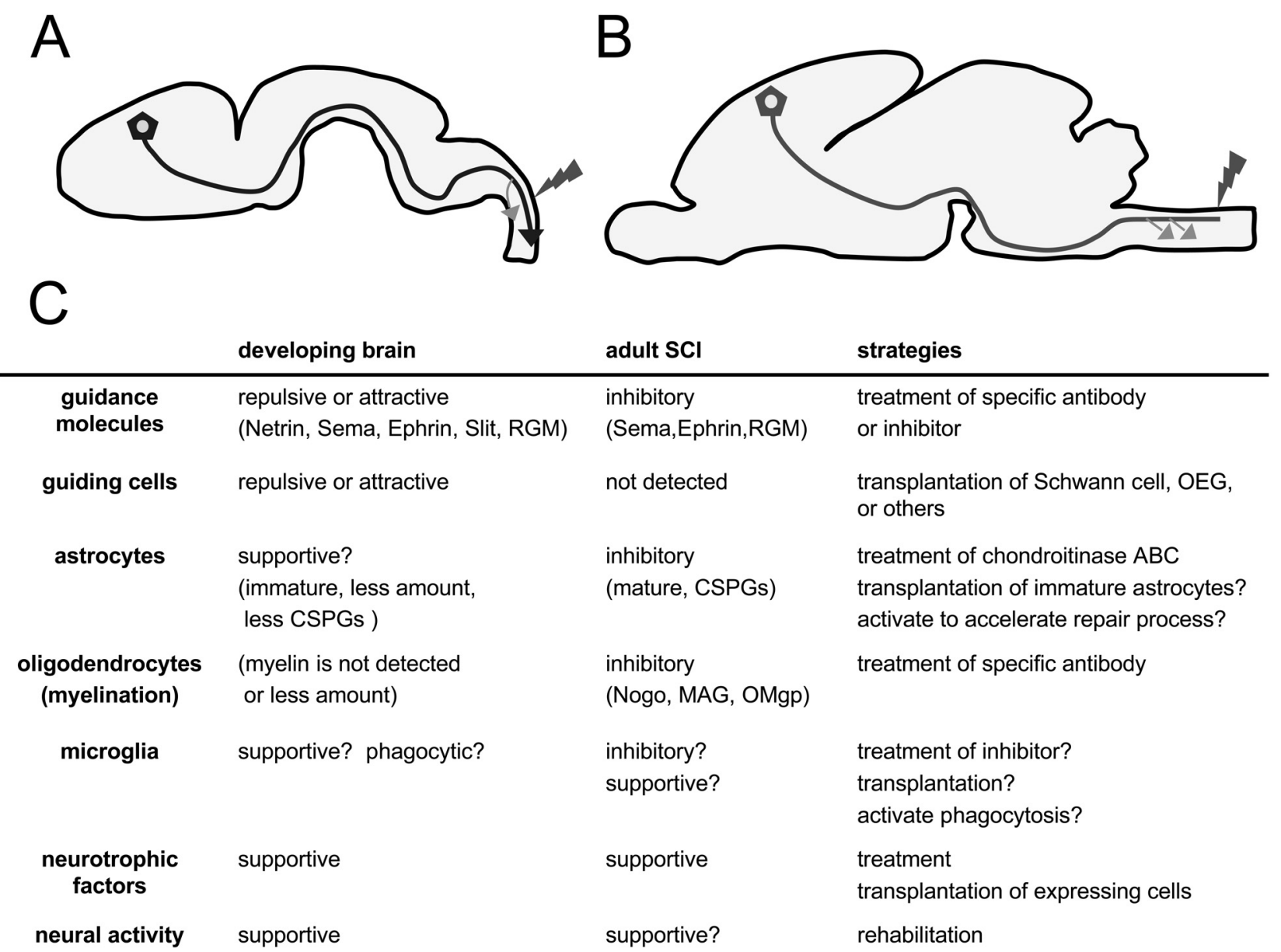

Figure I Comparison between the environments of a developing brain and an adult brain after SCI. A: Axons (blue line; in this case, CST) projected up to a long distance through a specific route. Even after the injury (red), axons can regenerate more extensively than in adults. Compensatory sprouting also occurs with high plastic ability (orange arrow). B: In the adult brain, axons (green line; in this case, CST) cannot regenerate after the injury (red), but compensatory sprouting occur in the rostral positions (orange arrows); however, the extent to which this occurs is not greater than that in the developing brain. C: Different components and their properties involved in the developing and adult brains after the $\mathrm{SCl}$. Each function is represented as the role toward axonal outgrowth (regeneration) and sprouting (plasticity). The properties of the components are presented within the parentheses. The strategies for the therapy targeting each component are represented in the right column. The details can be found in the text. 
neurons may possess a greater capacity of growth. It may be clear that younger neurons or certain types of neurons possess a much higher ability of elongating axons compared to other neurons, as suggested by the reports indicating that transplanted embryonic cortical neurons in the injured cortex can extend the axons even through the adult spinal cord (Gaillard et al 2007), and that neurons in different mouse strains have different regenerative abilities after SCI (Dimou et al 2006). However, many of the recent approaches have partially succeeded in regenerating axons by suppressing the inhibitory cues in the adult brain, suggesting that even the adult neurons have the ability to re-elongate axons. From this view, generating a favorable environment for axonal growth in the injured site should be one of the important goals for establishing therapeutic interventions.

\section{Axonal network formation by guidance molecules in the developing brain}

We should first understand how the complicated and precise axonal network is formed in the developing brain. During development, several steps are required to form a complex structure and for the functioning of the brain. First, undifferentiating neural stem cells or progenitor cells proliferate extensively around the ventricle called ventricular zone to reserve a large number of neurons and glial cells for the future adult brain. Next, some of these cells start migrating to specific areas and differentiating into neurons. After reaching the final position, the neurons start projecting the axons to the target area. In many cases, the axons are facilitated to pass through specific routes and targeted to specific areas. This process is very surprising because this navigation is quite precise, and in some cases, the neurons project the axons to a great distance from the cell bodies. Since 1990's, the mechanism of this precise navigation has been revealed by various studies identifying the axonal guidance molecules. Netrin, Ephrin, Semaphorin, and Slit are the representative guidance molecules (for review Huber et al 2003). In vitro culture system and the analyses from knockout mice have clearly revealed that these molecules have an important role in navigating axons in the developing brain. For example, corticospinal tract (CST), the main tract connecting the sensorimotor cortex to the spinal cord for regulating the motor function (Figure 1), is also navigated by these molecules. In the first step, Sema3A expressed in the upper layers of the cortex repulses the axons of neurons in the deeper layer (layer $\mathrm{V}$ in the future) to the deeper white matter (Polleux et al 1998, 2000). Slit2 then repulses the axons after passing the internal capsule, for projecting the specific route into the cerebral peduncle (Bagri et al 2002). After having passed the cerebral peduncle, most of the fibers cross the midline and go through to the contralateral side. It is indicated that Netrin and its receptors, Dcc and Unc5H3 contribute to this decussation (Finger et al 2002). While passing the spinal cord, Ephrin-B3 repulses the CST not to cross the midline (Kullander et al 2001; Yokoyama et al 2001).

Recent reports have demonstrated other important molecules responsible for guiding axons, morphogens. Morphogens - such as Sonic hedgehog (Shh), Fibroblast growth factor (Fgf), Bone morphogenetic protein (Bmp), and Wnts - are the signaling molecules that diffuse and establish a gradient in the embryonic tissues. This gradient signal plays a crucial role in arealizing the tissues by changing the cells from single type to heterogeneous populations. These molecules play a similar role in the developing CNS. The famous example is that of the developing spinal cord in which Shh, which is expressed in the most ventral place called floor plate, is diffused dorsally and establishes a gradient concentration. As a result, several clusters of neuronal populations are generated in the ventral spinal cord depending on the concentration of Shh (Jacob and Briscoe 2003). Intriguingly, recent papers have indicated that these morphogens regulate not only the specification of tissue areas and cell population, but also navigate the axons (for review Charron and TessierLavigne 2005). Again, CST passes through the spinal cord up to a long distance mainly in the first postnatal week in rodents (Gianino et al 1999; Joosten and Bär 1999). Interestingly, developing CST expresses Ryk, one of the Wnts receptors, and is pushed down by Wnts signals in the spinal cord after decussation (Liu et al 2005). Wnt1 and 5a are expressed in a rostral to caudal gradient that repulses the CST into lower levels. Thus, CST can be guided for a long distance to the final targets by Wnts signaling.

One ultimate strategy for facilitating definite regeneration after the SCI may be to reconstruct these guidance cues in precise positions spatially and temporally like in the developing brain. Joosten et al (1995) showed that injured CST in adult rats could regenerate by the local application of cervical spinal cord extracts which were harvested at the time that developing CST axons reached this spinal cord level. On the other hand, the injured axons could not regenerate when spinal cord extracts were harvested at younger or older age. This data implied that specifically organized expression of guidance molecules seen in the development is also optimal for regeneration. It is known, however, that some of these guidance molecules are still expressed in the adult developed 
brain in a different manner or are abnormally re-expressed at the lesion site. This appears to make the precise reconstruction of guidance cues difficult. In addition, some of these molecules are reported to suppress the regeneration of injured axons. Alternatively, recent researches have partly succeeded in promoting regeneration by suppressing the expression of these guidance molecules. We will focus on this issue in the later chapters.

\section{Guiding cells that facilitate axonal network formation in the developing brain and their transplantation}

Besides the axon guidance molecules, certain types of specific guiding cells navigate the axons in the developing brain. These cells were reported earlier as "guidepost cells" in the embryonic limb bud of grasshopper (Bentley and Caudy 1983), and in the following papers, several other types of navigating cells were identified in the corpus callosum (Silver and Ogawa 1983; Shu and Richards 2001), olfactory tract (Sato et al 1998), and thalamocortical axons (López-Bendito et al 2006) of the developing rodent brain. Although the existence of guiding cells in the developing CST is also speculated from the observation of immature astrocytes discovered in the route of CST in early postnatal days (Joosten and Gribnau 1989), unfortunately, there are no clear evidences regarding their role in guiding axons.

As developmentally, early brain tissues possess a favorable environment for axonal growth, implanting fetal nerve tissue may be a simple way of promoting regeneration after SCI. However, obtaining this tissue is extremely difficult, thus rendering its implantation for clinical therapy rather questionable. The next strategy is to transplant guiding cells specific to the axons in the spinal cord; however, as mentioned earlier, specific guiding cells for the CST or other axons in the spinal cord have not been identified yet. Hence, the ongoing approach is to transplant guiding or supportive cells that can be obtained from other parts of the body. Historically, two types of cell have mainly been attempted for conducting transplantation: the peripheral nerve (Schwann cells) (Richardson et al 1980; David and Aguayo 1981; Takami et al 2002) and olfactory ensheathing glial cells (OEG) (Li et al 1997; Ramón-Cueto et al 1998). These approaches were not designed from the mechanisms of developmental processes; rather, they were developed from the mechanism of regeneration and axonal outgrowth in the adult brain. Axons of PNS can regenerate more easily than those of CNS, raising the possibility that peripheral nerves or Schwann cells act as favorable substrates for axonal growth. OEGs are the specialized glial cells ensheathing olfactory axons of neurosensory cells in the olfactory epithelium. Neurosensory cells (and their axons, olfactory axons) are continuously replaced and newly formed in the adult, suggesting that OEGs support axonal outgrowth. These transplanted cells bridge the lesion site after SCI and, to a certain extent, effect regeneration and functional recovery. These experiments may provide us a new insight in to establishing therapeutic methods from the basic research on brain development: discoveries and identification of guiding cells in the developing brain may open a new strategy to promote regeneration.

\section{Distinct tissue responses in young and adult injured CNS: the role of glial cells}

One of the points of differences between adult and developing brain is that adult CNS includes not only neurons but also a large number of matured glial cells. These cells are clearly activated in the injured site to repair the tissue, which appears to affect the outgrowth of injured axons.

Astrocytes are the cells that are activated after the injury and form a glial scar to repair the injured tissue. Glial scar formation is an important process for tissue repair. Conditional and selective ablation of activated astrocytes after SCI delays the repair process and caused motor deficits (Faulkner et al 2004). Conditional ablation of astrocytic activation using Stat 3 conditional knockout model also diminishes the recovery (Okada et al 2006). These reports indicate that a glial scar plays an important role in tissue repair by protecting the neighboring intact tissues from excessive degeneration, inflammation, demyelination, etc. Unfortunately, although the glial scar is a key contributor to repair, it simultaneously inhibits axonal regeneration (Rudge and Silver 1990). An important factor that suppresses the regeneration expressed by astrocytes is chondroitin sulfate proteoglycans (CSPGs) (Mckeon et al 1991; Jones et al 2003; Tang et al 2003). CSPGs are glycoproteins within extracellular matrices that function as barriers that inhibit the penetration of regenerating axons into the lesion sites. By either treating chodroitinase $\mathrm{ABC}$, which is the bacterial enzyme that digests CSPGs, or by using transgenic mice that express chodroitinase $\mathrm{ABC}$ in astrocytes, it was possible to promote regeneration after SCI (Bradbury et al 2002; Cafferty et al 2007); although, functional recovery was not achieved in transgenic mice. 
In the developing brain, astrocytes are generated from neural progenitor cells in the later period of development compared with neurons (Temple 2001). Thus, astrocytic responses do not occur in early embryonic brain injury (Ueno et al 2006). SCI in early postnatal days activates astrocytes but no more remarkably than in adults (Barrett et al 1984; Firkins et al 1993) possibly due to the lower number of astrocytes and lesser extent of maturation. Interestingly, although CSPGs are basically considered as barriers to axonal elongation in the developing brain (Snow et al 1990; Katoh-Semba et al 1995), they are not upregulated remarkably in the young reactive astrocytes after an injury (Mckeon et al 1991; Dow et al 1994). It may imply that axons in a younger brain can regenerate easily due to the lack of inhibitory factors from activated astrocytes. Moreover, others reported that reactive astrocytes in the younger brains could be permissive for or promote axonal growth (Rudge and Silbver 1990; Bähr et al 1995). This suggests that there may be different types of astrocytes, particularly, an inhibitory and permissive type for axonal growth as indicated even in the amphibian which has a greater potential for regeneration (Reier 1979; Singer et al 1979). The permissive type also looks like a similar phenotype as seen in several regions of the developing brain as guiding cells (see previous chapter). Thus, understanding the mechanism of astroglial activation into different types and implanting supportive astrocytes into the lesion may establish a new approach to promote axonal outgrowth (Davies et al 2006).

Although, the reason for which scar formation is required to block regeneration is not clear, at least, the most important role of the scar should be finishing and enclosing the repairing (inflammatory) response to protect from neighboring intact CNS tissue. Thus, scar response should not be eliminated from the list of possible strategies that can be considered for the therapy. Instead, because scar inhibits the outgrowth of axons, completing the repair process speedily and compacting the scar to as small as possible, or deleting specific molecules that suppresses regeneration but not scar formation, should be the considered approach.

Oligodendrocytes are the glial cells that are involved in myelination. It is widely accepted that these cells (or its components and debris) also inhibit axonal regeneration post SCI. Earlier experiments performed by Schwab's group revealed that in the rats in which oligodendrocytes (and myelin) are deleted, axonal regeneration after SCI is promoted more than in control rats (Savio and Schwab 1990). Subsequently, they generated a monoclonal antibody known as IN-1 that recognizes myelin-associated inhibitory proteins, and revealed that treatment using this antibody promotes axonal regeneration (Schnell and Schwab 1990; Bregman et al 1995). Then, Nogo was identified as the inhibitory protein that is recognized by IN-1 (Chen et al 2000; GrandPré et al 2000; Prinjha et al 2000). Myelinassociated glycoprotein (MAG) (Mukhopadhyay et al 1994; McKerracher et al 1994), and oligodendrocyte myelin protein (OMgp) (Kottis et al 2002; Wang et al 2002) were also identified as the inhibitory proteins for axonal outgrowth. Surprisingly, all of these three inhibitory proteins exert their inhibitory function through one common receptor, Nogo-66 receptor (NgR) (Fournier et al 2001; Domeniconi et al 2002; Liu et al 2002; Wang et al 2002) and its receptor complex p75 (Wang et al 2002; Wong et al 2002; Yamashita et al 2002), Lingo-1 (Mi et al 2004), and TROY (Park et al 2005; Shao et al 2005) (for review, Yamashita et al 2005). Extensive studies using Nogo antibody (Schnell and Schwab 1990; Bregman et al 1995) and Nogo knockout mice (Kim et al 2003; Simonen et al 2003) and NgR (Kim et al 2004) have demonstrated that this is one of the critical factors inhibiting regeneration in SCI; although, several reports were unable to prove similar roles of Nogo and $\mathrm{NgR}$ as inhibitors (Zheng et al 2003, 2005). Similarly, MAG (Bartsch et al 1995), p75 (Song et al 2004) deficient mice do not undergo regeneration after SCI, but treatment using Lingo-1 antagonist promotes axonal sprouting (Ji et al 2006). Several controversial results regarding the role of myelin-associated proteins in regeneration suggest that the inhibitory cues may affect the injured axons through more varieties of molecules and through complicated mechanisms.

Myelination starts later in CNS development after P14 in the spinal cord of the rodents (Schwab and Schnell 1989; Joosten et al 1989; Hsu et al 2006). This may also imply that the strong capacity of regeneration in younger animals is achieved due to lesser amounts of myelin components, although Nogo is expressed early in postnatal period by neurons (Huber et al 2002). Interestingly, less amount of myelin can also enable the developing axons to display the plastic changes (plasticity) during the early postnatal period for learning and adapting to their external environment. This fact could also lead to understanding the mechanism that promotes plasticity after an adult CNS injury. Indeed, some studies succeeded in promoting plasticity after the injury by modifying myelin-components. We will discuss this issue in the next section.

Microglia is the last glial cell that is believed to be originated from mesenchymal lineage (monocyte or myeloid) (Chan et al 2007), which is different from other glial cells that 
are generated from neural progenitor cells (Temple 2001). One interesting aspect regarding microglia is that this cell has different phases or types that are beneficial and detrimental for axons. One direct evidence that microglia is an inhibitory factor for regeneration is that treatment using minocycline, an inhibitor of activation of microglia, promotes recovery by decreasing the dieback of CST and cell death of oligodendrocytes (Stirling et al 2004; Festoff et al 2006; Yune et al 2007). Depletion of hematogenous macrophages also promotes partial recovery (Popovich et al 1999). Since minocycline has an additional neuroprotective effect (Yong et al 2004), a selective ablation of microglial cells using transgenic mice (Lalancette-Hébert et al 2007) may provide us with more convincing results regarding the actual role of microglia in SCI. The beneficial aspects of these cells are suggested from the fact that coculturing microglia with neurons can promote the extension of neurites (Nakajima et al 1989; Chamak et al 1994; Bouhy et al 2006). Indeed, microglia express neurotrophic factors (Elkabes et al 1996; Dougherty et al 2000). One report suggested that later activation of microglial cells in vivo by treatment of GM-CSF after SCI facilitates regeneration possibly due to BDNF expression by microglia (Bouhy et al 2006). Some other studies also succeeded in promoting recovery by transplanting microglia/macrophages (Prewitt et al 1997; Rabchevsky and Streit 1997). Another beneficial role of microglia may be phagocytosis. As mentioned above, myelin-related protein is one of the key factors that inhibit regeneration. Microglia can phagocytose the myelin debris after CNS injury but not speedily and sufficiently (George and Griffin 1994; Buss and Schwab 2003). Thus, promoting the phagocytic ability may be one of the strategies that can be employed for therapy (Vallières et al 2006). Transplantation of macrophages that are prestimulated by peripheral nerves (myelin components) into injured site promotes the recovery of motor function (Rapalino et al 1998). Although it is not clear whether this beneficial effect is due to the enhancement of phagocytic ability, one can deduce that in some way, an appropriate activation of microglia/macrophage targeted to autologous tissue (possibly myelin) is protective and effective in repair and regeneration (for review, Schwartz et al 2006). In the developing brain, microglia infiltrate into the CNS around E10 in rodents and are believed to play a role in engulfing the dying apoptotic cells (Ashwell 1991). Interestingly, microglial cells express neurotrophic factors even in the developing brain (Elkabes et al 1996), and it is assumed that these cells may have some role to play in axonal growth (Chamak et al 1994; Streit 2001), although a direct in vivo evidence is deficient. In this case, understanding the role of microglia in the injured brain may offer an important clue regarding its role in development.

\section{Plasticity in development, and adult brain injuries}

It is known that after SCI, compensatory axonal sprouting occurs in the upper level of the lesion (Figure 1; Aoki et al 1986; Li et al 1994; Weidner et al 2001; Fouad et al 2001).

For a long time, the reason behind the occurrence of slight functional recovery, unless spinal axons regenerate, was unclear; however, Bareyre et al suggested that the new sprouting axons in the upper level establish a new contact with the intraspinal interneurons and form a new neural circuit that may contribute to partial recovery (Bareyre et al 2004). Interestingly, the temporal pattern of the newly generated sprouting appears to be significantly similar to the developmental process of CST. As described above, axons in the CST are elongated in early postnatal life, and after some "waiting period" (approximately 3 days), passing axons start establishing collaterals; in other words, they begin sprouting (O’Leary and Terashima 1988; Gianino et al 1999; Joosten and Bär 1999). Thus, an understanding of the mechanism of collateral formation in the developing brain will lead us to a new approach for promoting sprouting that may lead to functional recovery after SCI. In the developing brain, axonal collateral formation appears to be initiated by diffusible factors that emanate from their targets (Sato et al 1994; Joosten et al 1994). Although the cues that induce collateral formation in the spinal cord are unidentified, a potential cue may be neurotrophic factors. NT-3 and BDNF are known to promote axonal branching in a variety of neurons. Indeed, NT-3 enhances developmental sprouting in the spinal cord, and also in the injured adult spinal cord (Schnell et al 1994; Grill et al 1997; Zhou et al 2003). Although some recent papers reveal contrasting results on NT-3, and propound instead that providing BDNF treatment to the cell body of CST promotes sprouting (Hiebert et al 2002; Hagg et al 2005; Vavrek et al 2006).

Interestingly, similar factors appear to be used for controlling the developmental plasticity and plasticity after adult brain injury. Neural activity is the first factor that influences the plastic changes. Developing visual cortex is one of the extensively studied areas regarding plasticity in development. Neural inputs from both eyes through the thalamus compete with each other in the developing visual cortex through neural activity. This competition normally forms specific ocular dominance columns in the visual cortex that respond to alternative eyes. Intriguingly, monocular deprivation during 
the critical period, which is the window period during early postnatal days when plastic changes can occur, shifts the response of neurons in both columns toward the dominantly activated input from the opened eye (for review, Hensch 2005). Thus, neural activity appears to be the first step in inducing plasticity. In the case of SCI, many reports have indicated that rehabilitation - such as locomotor training and environmental enrichment, which supposedly enhance neural activity - promotes functional recovery in rodents (Lankhorst et al 2001; Van Meeteren et al 2003; Hutchinson et al 2004; Engesser-Cesar et al 2007). The mechanisms that improve function after rehabilitation are not fully understood; however, neural plasticity must be involved.

Neurotrophin is the next factor involved in plasticity. In the developing visual cortex, excess treatment or removal of BDNF, NT-4/5 prevents or delays ocular dominance formation (Cabelli et al 1995, 1997), and focal injection of NT-4/5 prevents the plastic shift in the visual cortex (Riddle et al 1995). This implies that axons from each eye compete with each other through limited amount of neurotrophins in an activity-dependent manner, and only the ones that can receive neurotrophic factors are stabilized. In the SCI, neurotrophic factors appear to enhance plastic changes via sprouting, as mentioned above. Thus, the precise treatment using neurotrophic factors and stimulation of neural activity (it is related to good rehabilitation strategies) should be one of the key strategies to enhance plasticity after SCI.

The last factor contributing to plasticity is inhibitory molecules. The increasing number of inhibitory factors during postnatal development appears to terminate or decrease the overall plasticity of neural connections. CSPGs that inhibit regeneration after SCI are one of the inhibitory factors that also decrease plasticity through the developing brain. CSPGs organize a perineuronal net as the extracellular matrix. Treatment using chondroitinase ABC degrades CSPGs and reactivates the plasticity toward monocular deprivation in the adult visual cortex (Pizzorusso et al 2002). Interestingly, increasing myelin formation also appears to terminate the plastic changes in the visual cortex of younger brain. It is reported that the critical period is delayed in the visual cortex of $\mathrm{NgR}$ deficient mice (McGee et al 2005). As observed in younger animals, myelin components also inhibit plasticity after adult brain injury. For example, in Nogo-/- and $\mathrm{NgR}-/-$ mice, sprouting (plasticity) of axons was promoted after CNS injury (Lee et al 2004; Cafferty and Strittmatter 2006), and blocking NgR signals also enhanced sprouting rostral to the lesion site after SCI (Li et al 2004, 2005; Li and Strittmatter 2003).
In conclusion, all these instances suggest that plasticity of axons in the developing brain and adult brain after the injury appear to involve similar mechanisms. Thus, understanding the mechanism of plasticity during development will offer an important clue for developing a new therapeutic strategy for SCI by promoting plasticity.

\section{Strategy for therapy: insights from guidance molecules}

The last insights obtained from the researches on development are that a number of axonal guidance molecules guiding axons during development are re-expressed by the glial and inflammatory cells after the injury or continuously expressed in adult CNS cells. By now, Netrin1 (Wehrle et al 2005), EphA4 (Goldshmit et al 2004), EphB2 (Bundesen et al 2003), Sema3, 7a (De Winter et al 2002; Pasterkamp et al 2003), and Slit1, 3 (Wehrle et al 2005) have been revealed to be expressed in the lesion site of SCI. Although these molecules have various roles in the repair process, such as activation of astrocytes (EphA4; Goldshmit et al 2004), scar formation (EphB2; Bundesen et al 2003), and migration of adult progenitor cells (Netrin1; Petit et al 2007), there are no doubts that some of these molecules also affect the outgrowth of injured axons. Sema3A is expressed mainly in the fibroblasts after injury (De Winter et al 2002), and the specific inhibitor of Sema3A clearly promotes the regeneration of axons (Kaneko et al 2006). We also demonstrated an additional example. Repulsive guidance Molecule (RGM), a glycosylphosphatidylinositol (GPI)-anchored membrane-bound protein, is another family of guidance molecules important for axonal development, which had been shown to navigate the optic nerve in the chick tectum to form a topographic map (Stahl et al 1990; Monnier et al 2002; for review, Yamashita et al 2007). We as well as others elucidated that RGMa is also expressed in the injured tissue including astrocytes, microglia, oligodendrocytes, and neurons (Schwab et al 2005; Hata et al 2006). Treatment with RGMa antibody after the SCI in a rat promotes axonal regeneration and synapse formation, and recovers behavioral function, as evaluated by BBB test (Hata et al 2006; Kyoto et al 2007). This data suggests that RGMa is one of the key inhibitory factors for axonal regeneration. Morphogens are also candidate molecules that inhibit regeneration. We have recently reported that BMP-2/4 expression is elevated in the lesion of SCI and administration of Noggin, a soluble BMP antagonist, promotes regeneration of CST (Matsuura et al 2008). BMP is known as a repulsive guidance molecule to commissural axons in the developing spinal cord (Augsburger et al 1999; Butler and Dodd 2003), 
suggesting that similar repulsive factors re-expressed in the adult lesion site.

One important issue is that the spinal cord has various descending and ascending axons and these have different regenerative reaction to therapeutic approaches (Deumens et al 2005). In the developing brain, axons in each axon tract have different set of receptors for guidance molecules to select specific route for the targets. It appears that each tract in adult also has specific molecular profiles for regeneration. For example, treatment of Sema3A-inhibitor promotes regeneration of raphespinal tract but not CST (Kaneko et al 2006). It was shown that raphespinal axons express neuropilin-1, the receptor to mediate repulsive effect of Sema3A. Netrin-1 is expressed in oligodendrocytes, cells of central canal, and the meninges in adult SCI, and inhibits axonal growth through the receptor, Unc5 (Löw et al 2008). Implantation of Netrin-1 expressing fibroblasts inhibits the regeneration of rubrospinal fibers which express Unc5A, but not CGRP-positive nociceptive axons which do not express Unc5. Thus, when the effects of the treatment are examined, we should consider which axons express receptors for guidance molecules, which axons regenerate after treatments, and how the regeneration of specific axons contribute to behavioral appearance.

Other targets are the downstream signaling molecules of inhibitory cues. Recent reports indicate that the small GTP-binding protein Rho and its effectors, ie, ROCK, are the key molecules that mediate inhibitory signals for axonal growth (for review see Mueller et al 2005; Kubo et al 2007). Importantly, Rho is a common downstream molecule of many repulsive cues, including RGM (Hata et al 2006), myelin-associated proteins through p75 (Yamashita and Tohyama 2003), CSPGs (Monnier et al 2003), and members of the Semaphorin and Ephrin families (Wahl et al 2000; Swiercz et al 2002). Thus, inhibiting the common pathway that mediates repulsion is one of the promising targets for therapy. Indeed, treatment with ROCK inhibitors, promotes axonal regeneration after SCI (Dergham et al 2002; Fournier et al 2003; Tanaka et al 2004). Understanding the detailed molecular mechanism of the inhibitory signals will reveal new targets for therapy.

Many discoveries regarding the role of various molecules and their effects in the case of SCI have emerged. This indicates that multiple inhibitory factors suppress regeneration. In fact, regeneration can be achieved but not to a great extent in each report. The approaches therefore shift to the use of a combination of several therapeutic approaches. For example, treatment with NT3 and an antibody of myelinassociated inhibitory proteins (IN-1) (Schnell et al 1994), transplantation of fetal spinal cord and neurotrophic factors (Bregman et al 1997), chondroitinase ABC and cellular transplantation (Fouad et al 2005) etc have succeeded in promoting regeneration to a much greater extent than individual therapeutic approaches. Overall, combinational strategies that promote the completion of the repair process including inflammation and scar formation rapidly and in a compact manner, excluding the inhibitory factors for regeneration, bridging the lesion site, and facilitating the regeneration and sprouting of axons, should be considered for designing new therapeutic approaches. As the number of possible combinations that should be tested is already very large, greater efforts will be required to establish appropriate therapeutic methods. The scientific community working on SCI therefore needs to be increased and collaborate with each other. Furthermore, developmental neuroscientists can rightly contribute to this community.

In conclusion, an important aspect gathered from a large number of studies is that behavioral recovery after the injury by various treatments and methods is well correlated with the histological changes that occur in axons, ie axonal regeneration and sprouting. This implies that axonal regeneration and sprouting are crucial for behavioral recovery. Thus, promoting axonal elongation and sprouting is now one of the most important strategies to be employed for developing a new therapeutic method. In this case, basic research on brain development will reveal important clues.

\section{References}

Aoki M, Fujito Y, Satomi H, et al. 1986. The possible role of collateral sprouting in the functional restitution of corticospinal connections after spinal hemisection. Neurosci Res, 3:617-27.

Ashwell K. 1991. The distribution of microglia and cell death in the fetal rat forebrain. Brain Res Dev Brain Res, 58:1-12.

Augsburger A, Schuchardt A, Hoskins S, et al. 1999. BMPs as mediators of roof plate repulsion of commissural neurons. Neuron, 24:127-41.

Bagri A, Marín O, Plump AS, et al. 2002. Slit proteins prevent midline crossing and determine the dorsoventral position of major axonal pathways in the mammalian forebrain. Neuron, 33:233-48.

Bähr M, Przyrembel C, Bastmeyer M. 1995. Astrocytes from adult rat optic nerves are nonpermissive for regenerating retinal ganglion cell axons. Exp Neurol, 131:211-20.

Bareyre FM, Kerschensteiner M, Raineteau O, et al. 2004. The injured spinal cord spontaneously forms a new intraspinal circuit in adult rats. Nat Neurosci, 7:269-77.

Barrett CP, Donati EJ, Guth L. 1984. Differences between adult and neonatal rats in their astroglial response to spinal injury. Exp Neurol, $84: 374-85$.

Bartsch U, Bandtlow CE, Schnell L, et al. 1995. Lack of evidence that myelin-associated glycoprotein is a major inhibitor of axonal regeneration in the CNS. Neuron, 15:1375-81.

Bates CA, Stelzner DJ. 1993. Extension and regeneration of corticospinal axons after early spinal injury and the maintenance of corticospinal topography. Exp Neurol, 123:106-17.

Bentley D, Caudy M. 1983. Pioneer axons lose directed growth after selective killing of guidepost cells. Nature, 304:62-5. 
Bernstein DR, Stelzner DJ. 1983. Plasticity of the corticospinal tract following midthoracic spinal injury in the postnatal rat. J Comp Neurol, 221:382-400.

Bouhy D, Malgrange B, Multon S, et al. 2006. Delayed GM-CSF treatment stimulates axonal regeneration and functional recovery in paraplegic rats via an increased BDNF expression by endogenous macrophages. FASEB J, 20:1239-41.

Bradbury EJ, Moon LD, Popat RJ, et al. 2002. Chondroitinase ABC promotes functional recovery after spinal cord injury. Nature, 416:636-40.

Bregman BS, Kunkel-Bagden E, McAtee M, et al. 1989. Extension of the critical period for developmental plasticity of the corticospinal pathway. J Comp Neurol, 282:355-70.

Bregman BS, Kunkel-Bagden E, Reier PJ, et al. 1993. Recovery of function after spinal cord injury: mechanisms underlying transplant-mediated recovery of function differ after spinal cord injury in newborn and adult rats. Exp Neurol, 123:3-16.

Bregman BS, Kunkel-Bagden E, Schnell L, et al. 1995. Recovery from spinal cord injury mediated by antibodies to neurite growth inhibitors. Nature, 378:498-501.

Bregman BS, McAtee M, Dai HN, et al. 1997. Neurotrophic factors increase axonal growth after spinal cord injury and transplantation in the adult rat. Exp Neurol, 148:475-94.

Bundesen LQ, Scheel TA, Bregman BS, et al. 2003. Ephrin-B2 and EphB2 regulation of astrocyte-meningeal fibroblast interactions in response to spinal cord lesions in adult rats. J Neurosci, 23:7789-800.

Buss A, Schwab ME. 2003. Sequential loss of myelin proteins during Wallerian degeneration in the rat spinal cord. Glia, 42:424-32.

Butler SJ, Dodd J. 2003. A role for BMP heterodimers in roof plate-mediated repulsion of commissural axons. Neuron, 38:389-401.

Cabelli RJ, Hohn A, Shatz CJ. 1995. Inhibition of ocular dominance column formation by infusion of NT-4/5 or BDNF. Science, 267:1662-6.

Cabelli RJ, Shelton DL, Segal RA, et al. 1997. Blockade of endogenous ligands of trkB inhibits formation of ocular dominance columns. Neuron, 19:63-76.

Cafferty WB, Strittmatter SM. 2006. The Nogo-Nogo receptor pathway limits a spectrum of adult CNS axonal growth. J Neurosci, 26:12242-50.

Cafferty WB, Yang SH, Duffy PJ, et al. 2007. Functional axonal regeneration through astrocytic scar genetically modified to digest chondroitin sulfate proteoglycans. J Neurosci, 27:2176-85.

Chamak B, Morandi V, Mallat M. 1994. Brain macrophages stimulate neurite growth and regeneration by secreting thrombospondin. $J$ Neurosci Res, 38:221-33.

Chan WY, Kohsaka S, Rezaie P. 2007. The origin and cell lineage of microglia: new concepts. Brain Res Rev, 53:344-54.

Charron F, Tessier-Lavigne M. 2005. Novel brain wiring functions for classical morphogens: a role as graded positional cues in axon guidance. Development, 132:2251-62.

Chen MS, Huber AB, van der Haar ME, et al. 2000. Nogo-A is a myelinassociated neurite outgrowth inhibitor and an antigen for monoclonal antibody IN-1. Nature, 403:434-9.

David S, Aguayo AJ. 1981. Axonal elongation into peripheral nervous system "bridges" after central nervous system injury in adult rats. Science, 214:931-3.

Davies JE, Huang C, Proschel C, et al. 2006. Astrocytes derived from glialrestricted precursors promote spinal cord repair. J Biol, 5:7.

De Winter F, Oudega M, Lankhorst AJ, et al. 2002. Injury-induced class 3 semaphorin expression in the rat spinal cord. Exp Neurol, 175:61-75.

Dergham P, Ellezam B, Essagian C, et al. 2002. Rho signaling pathway targeted to promote spinal cord repair. J Neurosci, 22:6570-7.

Deumens R, Koopmans GC, Joosten EA. 2005. Regeneration of descending axon tracts after spinal cord injury. Prog Neurobiol, 77:57-89.

Dimou L, Schnell L, Montani L, et al. 2006. Nogo-A-deficient mice reveal strain-dependent differences in axonal regeneration. J Neurosci, 26:5591-603.

Domeniconi M, Cao Z, Spencer T, et al. 2002. Myelin-associated glycoprotein interacts with the Nogo66 receptor to inhibit neurite outgrowth Neuron, 35:283-90.
Dougherty KD, Dreyfus CF, Black IB. 2000. Brain-derived neurotrophic factor in astrocytes, oligodendrocytes, and microglia/macrophages after spinal cord injury. Neurobiol Dis, 7:574-85.

Dow KE, Ethell DW, Steeves JD, et al. 1994. Molecular correlates of spinal cord repair in the embryonic chick: heparan sulfate and chondroitin sulfate proteoglycans. Exp Neurol, 128:233-8.

Elkabes S, DiCicco-Bloom EM, Black IB. 1996. Brain microglia/macrophages express neurotrophins that selectively regulate microglial proliferation and function. $J$ Neurosci, 16:2508-21.

Engesser-Cesar C, Ichiyama RM, Nefas AL,et al. 2007. Wheel running following spinal cord injury improves locomotor recovery and stimulates serotonergic fiber growth. Eur J Neurosci, 25:1931-9.

Faulkner JR, Herrmann JE, Woo MJ, et al. 2004. Reactive astrocytes protect tissue and preserve function after spinal cord injury. $J$ Neurosci, 24:2143-55.

Festoff BW, Ameenuddin S, Arnold PM, et al. 2006. Minocycline neuroprotects, reduces microgliosis, and inhibits caspase protease expression early after spinal cord injury. $J$ Neurochem, 97:1314-26.

Finger JH, Bronson RT, Harris B, et al. 2002. The netrin 1 receptors Unc5h3 and Dcc are necessary at multiple choice points for the guidance of corticospinal tract axons. J Neurosci, 22:10346-56.

Firkins SS, Bates CA, Stelzner DJ. 1993. Corticospinal tract plasticity and astroglial reactivity after cervical spinal injury in the postnatal rat. Exp Neurol, 120:1-15.

Fouad K, Pedersen V, Schwab ME, et al. 2001. Cervical sprouting of corticospinal fibers after thoracic spinal cord injury accompanies shifts in evoked motor responses. Curr Biol, 11:1766-70.

Fouad K, Schnell L, Bunge MB, et al. 2005. Combining Schwann cell bridges and olfactory-ensheathing glia grafts with chondroitinase promotes locomotor recovery after complete transection of the spinal cord. J Neurosci, 25:1169-78.

Fournier AE, GrandPre T, Strittmatter SM. 2001. Identification of a receptor mediating Nogo-66 inhibition of axonal regeneration. Nature, 409:341-6.

Fournier AE, Takizawa BT, Strittmatter SM. 2003. Rho kinase inhibition enhances axonal regeneration in the injured CNS. $J$ Neurosci, 23:1416-23.

Gaillard A, Prestoz L, Dumartin B, et al. 2007. Reestablishment of damaged adult motor pathways by grafted embryonic cortical neurons. Nat Neurosci, 10:1294-9.

George R, Griffin JW. 1994. Delayed macrophage responses and myelin clearance during Wallerian degeneration in the central nervous system: the dorsal radiculotomy model. Exp Neurol, 129:225-36.

Gianino S, Stein SA, Li H, et al. 1999. Postnatal growth of corticospinal axons in the spinal cord of developing mice. Brain Res Dev Brain Res, 112:189-204.

George R, Griffin JW. 1994. Delayed macrophage responses and myelin clearance during Wallerian degeneration in the central nervous system: the dorsal radiculotomy model. Exp Neurol, 129:225-36.

Goldshmit Y, Galea MP, Wise G, et al. 2004. Axonal regeneration and lack of astrocytic gliosis in EphA4-deficient mice. J Neurosci, 24:10064-73.

GrandPré T, Nakamura F, Vartanian T, et al. 2000. Identification of the Nogo inhibitor of axon regeneration as a Reticulon protein. Nature, 403:439-44.

Grill R, Murai K, Blesch A, et al. 1997. Cellular delivery of neurotrophin-3 promotes corticospinal axonal growth and partial functional recovery after spinal cord injury. J Neurosci, 17:5560-72.

Hagg T, Baker KA, Emsley JG, et al. 2005. Prolonged local neurotrophin-3 infusion reduces ipsilateral collateral sprouting of spared corticospinal axons in adult rats. Neuroscience, 130:875-87.

Harel NY, Strittmatter SM. 2006. Can regenerating axons recapitulate developmental guidance during recovery from spinal cord injury? Nat Rev Neurosci, 7:603-16.

Hata K, Fujitani M, Yasuda Y, et al. 2006. RGMa inhibition promotes axonal growth and recovery after spinal cord injury. J Cell Biol, 173:47-58. 
Hensch TK. Critical period plasticity in local cortical circuits. 2005. Nat Rev Neurosci, 6:877-88.

Hiebert GW, Khodarahmi K, McGraw J, et al. 2002. Brain-derived neurotrophic factor applied to the motor cortex promotes sprouting of corticospinal fibers but not regeneration into a peripheral nerve transplant. J Neurosci Res, 69:160-8.

Hsu JY, Stein SA, Xu XM. 2006. Development of the corticospinal tract in the mouse spinal cord: a quantitative ultrastructural analysis. Brain Res, 1084:16-27.

Huber AB, Kolodkin AL, Ginty DD, et al. 2003. Signaling at the growth cone: ligand-receptor complexes and the control of axon growth and guidance. Anпи Rev Neurosci, 26:509-63.

Huber AB, Weinmann O, Brösamle C, et al. 2002. Patterns of Nogo mRNA and protein expression in the developing and adult rat and after CNS lesions. J Neurosci, 22:3553-67.

Hutchinson KJ, Gómez-Pinilla F, Crowe MJ, et al. 2004. Three exercise paradigms differentially improve sensory recovery after spinal cord contusion in rats. Brain, 127:1403-14.

Iwashita Y, Kawaguchi S, Murata M. 1994. Restoration of function by replacement of spinal cord segments in the rat. Nature, 367:167-70.

Jacob J, Briscoe J. 2003. Gli proteins and the control of spinal-cord patterning. EMBO Rep, 4:761-5.

Ji B, Li M, Wu WT, et al. 2006. LINGO-1 antagonist promotes functional recovery and axonal sprouting after spinal cord injury. Mol Cell Neurosci, 33:311-20.

Jones LL, Margolis RU, Tuszynski MH. 2003. The chondroitin sulfate proteoglycans neurocan, brevican, phosphacan, and versican are differentially regulated following spinal cord injury. Exp Neurol, 182:399-411

Joosten EA, Bär DP. 1999. Axon guidance of outgrowing corticospinal fibres in the rat. J Anat, 194:15-32.

Joosten EA, Bär DP, Gispen WH. 1995. Directional regrowth of lesioned corticospinal tract axons in adult rat spinal cord. Neuroscience, 69:619-26

Joosten EA, Gispen WH, Bär PR. 1994. Tropism and corticospinal target selection in the rat. Neuroscience, 59:33-41.

Joosten EA, Gribnau AA. 1989. Astrocytes and guidance of outgrowing corticospinal tract axons in the rat. An immunocytochemical study using anti-vimentin and anti-glial fibrillary acidic protein. Neuroscience, 31:439-52.

Joosten EA, Gribnau AA, Dederen PJ. 1989. Postnatal development of the corticospinal tract in the rat. An ultrastructural anterograde HRP study. Anat Embryol, 179:449-56.

Kaneko S, Iwanami A, Nakamura M, et al. 2006. A selective Sema3A inhibitor enhances regenerative responses and functional recovery of the injured spinal cord. Nat Med, 12:1380-9.

Katoh-Semba R, Matsuda M, Kato K, et al. 1995. Chondroitin sulphate proteoglycans in the rat brain: candidates for axon barriers of sensory neurons and the possible modification by laminin of their actions. Eur J Neurosci, 7:613-21.

Kim JE, Li S, GrandPré T, et al. 2003. Axon regeneration in young adult mice lacking Nogo-A/B. Neuron, 38:187-99.

Kim JE, Liu BP, Park JH, et al. 2004. Nogo-66 receptor prevents raphespinal and rubrospinal axon regeneration and limits functional recovery from spinal cord injury. Neuron, 44:439-51.

Kottis V, Thibault P, Mikol D, et al. 2002. Oligodendrocyte-myelin glycoprotein (OMgp) is an inhibitor of neurite outgrowth. J Neurochem, $82: 1566-9$.

Kubo T, Hata K, Yamaguchi A, et al. 2007. Rho-ROCK inhibitors as emerging strategies to promote nerve regeneration. Curr Pharm Des, 13:2493-9.

Kullander K, Croll SD, Zimmer M, et al. 2001. Ephrin-B3 is the midline barrier that prevents corticospinal tract axons from recrossing, allowing for unilateral motor control. Genes Dev, 15:877-88.

Kyoto A, Hata K, Yamashita T. 2007. Synapse formation of the corticospinal axons is enhanced by RGMa inhibition after spinal cord injury. Brain Res, 1186:74-86.
Lalancette-Hébert M, Gowing G, Simard A, et al. 2007. Selective ablation of proliferating microglial cells exacerbates ischemic injury in the brain. J Neurosci, 27:2596-605.

Lankhorst AJ, ter Laak MP, van Laar TJ, et al. 2001. Effects of enriched housing on functional recovery after spinal cord contusive injury in the adult rat. $J$ Neurotrauma, 18:203-15.

Lee JK, Kim JE, Sivula M, et al. 2004. Nogo receptor antagonism promotes stroke recovery by enhancing axonal plasticity. $J$ Neurosci, 24:6209-17.

Li S, Strittmatter SM. 2003. Delayed systemic Nogo-66 receptor antagonist promotes recovery from spinal cord injury. J Neurosci, 23:4219-27.

Li S, Liu BP, Budel S, et al. 2004. Blockade of Nogo-66, myelin-associated glycoprotein, and oligodendrocyte myelin glycoprotein by soluble Nogo-66 receptor promotes axonal sprouting and recovery after spinal injury. J Neurosci, 24:10511-20.

Li S, Kim JE, Budel S, et al. 2005. Transgenic inhibition of Nogo-66 receptor function allows axonal sprouting and improved locomotion after spinal injury. Mol Cell Neurosci, 29:26-39.

Li WW, Yew DT, Chuah MI, et al. 1994. Axonal sprouting in the hemisected adult rat spinal cord. Neuroscience, 61:133-9.

Li Y, Field PM, Raisman G. 1997. Repair of adult rat corticospinal tract by transplants of olfactory ensheathing cells. Science, 277:2000-2.

Liu BP, Fournier A, GrandPré T, et al. 2002. Myelin-associated glycoprotein as a functional ligand for the Nogo-66 receptor. Science, 297:1190-3.

Liu Y, Shi J, Lu CC, et al. 2005. Ryk-mediated Wnt repulsion regulates posterior-directed growth of corticospinal tract. Nat Neurosci, 8:1151-9.

López-Bendito G, Cautinat A, Sánchez JA, et al. 2006. Tangential neuronal migration controls axon guidance: a role for neuregulin-1 in thalamocortical axon navigation. Cell, 125:127-42.

Löw K, Culbertson M, Bradke F, et al. 2008. Netrin-1 is a novel myelinassociated inhibitor to axon growth. J Neurosci, 28:1099-108.

Matsuura I, Taniguchi J, Hata K, et al. 2008. BMP inhibition enhances axonal growth and functional recovery after spinal cord injury. $J \mathrm{Neu}$ rochem, Mar 4 [Epub ahead of print].

McGee AW, Yang Y, Fischer QS, et al. 2005. Experience-driven plasticity of visual cortex limited by myelin and Nogo receptor. Science, 309:2222-6.

McKeon RJ, Schreiber RC, Rudge JS, et al. 1991. Reduction of neurite outgrowth in a model of glial scarring following CNS injury is correlated with the expression of inhibitory molecules on reactive astrocytes. J Neurosci, 11:3398-411.

McKerracher L, David S, Jackson DL, et al. 1994. Identification of myelinassociated glycoprotein as a major myelin-derived inhibitor of neurite growth. Neuron, 13:805-11.

Mi S, Lee X, Shao Z et al. 2004. LINGO-1 is a component of the Nogo-66 receptor/p75 signaling complex. Nat Neurosci, 7:221-8.

Monnier PP, Sierra A, Macchi P, et al. 2002. RGM is a repulsive guidance molecule for retinal axons. Nature, 419:392-5.

Monnier PP, Sierra A, Schwab JM, et al. 2003. The Rho/ROCK pathway mediates neurite growth-inhibitory activity associated with the chondroitin sulfate proteoglycans of the CNS glial scar. Mol Cell Neurosci, 22:319-30.

Mueller BK, Mack H, Teusch N. 2005. Rho kinase, a promising drug target for neurological disorders. Nat Rev Drug Discov, 4:387-98.

Mukhopadhyay G, Doherty P, Walsh FS, et al. 1994. A novel role for myelin-associated glycoprotein as an inhibitor of axonal regeneration. Neuron, 13:757-67.

Nakajima K, Hamanoue M, Shimojo M, et al. 1989. Characterization of microglia isolated from a primary culture of embryonic rat brain by a simplified method. Biomed Res, 10:411-23.

O'Leary DD, Terashima T. 1988. Cortical axons branch to multiple subcortical targets by interstitial axon budding: implications for target recognition and "waiting periods". Neuron, 1:901-10.

Okada S, Nakamura M, Katoh H, et al. 2006. Conditional ablation of Stat3 or Socs 3 discloses a dual role for reactive astrocytes after spinal cord injury. Nat Med, 12:829-34. 
Park JB, Yiu G, Kaneko S, et al. 2005. A TNF receptor family member, TROY, is a coreceptor with Nogo receptor in mediating the inhibitory activity of myelin inhibitors. Neuron, 45:345-51.

Pasterkamp RJ, Peschon JJ, Spriggs MK, et al. 2003. Semaphorin 7A promotes axon outgrowth through integrins and MAPKs. Nature, 424:398-405.

Petit A, Sellers DL, Liebl DJ, et al. 2007. Adult spinal cord progenitor cells are repelled by netrin-1 in the embryonic and injured adult spinal cord. Proc Natl Acad Sci USA, 104:17837-42.

Pizzorusso T, Medini P, Berardi N, et al. 2002. Reactivation of ocular dominance plasticity in the adult visual cortex. Science, 298:1248-51.

Polleux F, Giger RJ, Ginty DD, et al. 1998. Patterning of cortical efferent projections by semaphorin-neuropilin interactions. Science, 282:1904-6.

Polleux F, Morrow T, Ghosh A. 2000. Semaphorin 3A is a chemoattractant for cortical apical dendrites. Nature, 404:567-73.

Popovich PG, Guan Z, Wei P, et al. 1999. Depletion of hematogenous macrophages promotes partial hindlimb recovery and neuroanatomica repair after experimental spinal cord injury. Exp Neurol, 158:351-65

Prewitt CM, Niesman IR, Kane CJ, et al. 1997. Activated macrophage/ microglial cells can promote the regeneration of sensory axons into the injured spinal cord. Exp Neurol, 148:433-43.

Prinjha R, Moore SE, Vinson M, et al. 2000. Inhibitor of neurite outgrowth in humans. Nature, 403:383-4.

Ramón-Cueto A, Plant GW, Avila J, et al. 1998. Long-distance axonal regeneration in the transected adult rat spinal cord is promoted by olfactory ensheathing glia transplants. J Neurosci, 18:3803-15.

Rabchevsky AG, Streit WJ. 1997. Grafting of cultured microglial cells into the lesioned spinal cord of adult rats enhances neurite outgrowth. $J$ Neurosci Res, 47:34-48.

Rapalino O, Lazarov-Spiegler O, Agranov E, et al. 1998. Implantation of stimulated homologous macrophages results in partial recovery of paraplegic rats. Nat Med, 4:814-21.

Reier PJ. 1979. Penetration of grafted astrocytic scars by regenerating optic nerve axons in Xenopus tadpoles. Brain Res, 164:61-8.

Richardson PM, McGuinness UM, Aguayo AJ. 1980. Axons from CNS neurons regenerate into PNS grafts. Nature, 284:264-5.

Riddle DR, Lo DC, Katz LC. 1995. NT-4-mediated rescue of lateral geniculate neurons from effects of monocular deprivation. Nature, 378:189-91.

Rudge JS, Silver J. 1990. Inhibition of neurite outgrowth on astroglial scars in vitro. $J$ Neurosci, 10:3594-603.

Sato M, Lopez-Mascaraque L, Heffner CD, et al. 1994. Action of a diffusible target-derived chemoattractant on cortical axon branch induction and directed growth. Neuron, 13:791-803.

Sato Y, Hirata T, Ogawa M, et al. 1998. Requirement for early-generated neurons recognized by monoclonal antibody lot 1 in the formation of lateral olfactory tract. $J$ Neurosci, 18:7800-10.

Savio T, Schwab ME. 1990. Lesioned corticospinal tract axons regenerate in myelin-free rat spinal cord. Proc Natl Acad Sci USA, 87:4130-3.

Schnell L, Schneider R, Kolbeck R, et al. 1994. Neurotrophin-3 enhances sprouting of corticospinal tract during development and after adult spinal cord lesion. Nature, 367:170-3.

Schnell L, Schwab ME. 1990. Axonal regeneration in the rat spinal cord produced by an antibody against myelin-associated neurite growth inhibitors. Nature, 343:269-72.

Schwab ME, Bartholdi D. 1996. Degeneration and regeneration of axons in the lesioned spinal cord. Physiol Rev, 76:319-70.

Schwab JM, Conrad S, Monnier PP, et al. 2005. Spinal cord injury-induced lesional expression of the repulsive guidance molecule (RGM). Eur J Neurosci, 21:1569-76.

Schwab ME, Schnell L. 1989. Region-specific appearance of myelin constituents in the developing rat spinal cord. J Neurocytol, 18:161-9.

Schwartz M, Butovsky O, Brück W, et al. 2006. Microglial phenotype: is the commitment reversible? Trends Neurosci, 29:68-74.

Shao Z, Browning JL, Lee X, et al. 2005. TAJ/TROY, an orphan TNF receptor family member, binds Nogo-66 receptor 1 and regulates axonal regeneration. Neuron, 45:353-9.
Shu T, Richards LJ. 2001. Cortical axon guidance by the glial wedge during the development of the corpus callosum. J Neurosci, 21:2749-58.

Silver J, Ogawa MY. 1983. Postnatally induced formation of the corpus callosum in acallosal mice on glia-coated cellulose bridges. Science, 220:1067-9.

Simonen M, Pedersen V, Weinmann O, et al. 2003. Systemic deletion of the myelin-associated outgrowth inhibitor Nogo-A improves regenerative and plastic responses after spinal cord injury. Neuron, 38:201-11.

Singer M, Nordlander RH, Egar M. 1979. Axonal guidance during embryogenesis and regeneration in the spinal cord of the newt: the blueprint hypothesis of neuronal pathway patterning. J Comp Neurol, 185:1-21.

Snow DM, Steindler DA, Silver J. 1990. Molecular and cellular characterization of the glial roof plate of the spinal cord and optic tectum: a possible role for a proteoglycan in the development of an axon barrier. Dev Biol, 138:359-76.

Song XY, Zhong JH, Wang X, et al. 2004. Suppression of p75NTR does not promote regeneration of injured spinal cord in mice. $J$ Neurosci, 24:542-6.

Stahl B, Müller B, von Boxberg Y, et al. 1990. Biochemical characterization of a putative axonal guidance molecule of the chick visual system. Neuron, 5:735-43.

Stirling DP, Khodarahmi K, Liu J, et al. 2004. Minocycline treatment reduces delayed oligodendrocyte death, attenuates axonal dieback, and improves functional outcome after spinal cord injury. J Neurosci, 24:2182-90.

Streit WJ. 2001. Microglia and macrophages in the developing CNS. Neurotoxicology, 22:619-24.

Swiercz JM, Kuner R, Behrens J, et al. 2002. Plexin-B1 directly interacts with PDZ-RhoGEF/LARG to regulate RhoA and growth cone morphology. Neuron, 35:51-63.

Takami T, Oudega M, Bates ML, et al. 2002. Schwann cell but not olfactory ensheathing glia transplants improve hindlimb locomotor performance in the moderately contused adult rat thoracic spinal cord. $J$ Neurosci, 22:6670-81.

Tanaka H, Yamashita T, Yachi K, et al. 2004. Cytoplasmic p21(Cip1/WAF1) enhances axonal regeneration and functional recovery after spinal cord injury in rats. Neuroscience, 127:155-64.

Tang X, Davies JE, Davies SJ. 2003. Changes in distribution, cell associations, and protein expression levels of NG2, neurocan, phosphacan, brevican, versican V2, and tenascin-C during acute to chronic maturation of spinal cord scar tissue. J Neurosci Res, 71:427-44.

Temple S. 2001. The development of neural stem cells. Nature, 414:112-17.

Ueno M, Katayama K, Yamauchi H, et al. 2006. Repair process of fetal brain after 5-azacytidine-induced damage. Eur J Neurosci, 24:2758-68.

Vallières N, Berard JL, David S, et al. 2006. Systemic injections of lipopolysaccharide accelerates myelin phagocytosis during Wallerian degeneration in the injured mouse spinal cord. Glia, 53:103-13.

Van Meeteren NL, Eggers R, Lankhorst AJ, et al. 2003. Locomotor recovery after spinal cord contusion injury in rats is improved by spontaneous exercise. J Neurotrauma, 20:1029-37.

Vavrek R, Girgis J, Tetzlaff W, et al. 2006. BDNF promotes connections of corticospinal neurons onto spared descending interneurons in spinal cord injured rats. Brain, 129:1534-45.

Wahl S, Barth H, Ciossek T, et al. 2000. Ephrin-A5 induces collapse of growth cones by activating Rho and Rho kinase. J Cell Biol, 149:263-70.

Wang KC, Kim JA, Sivasankaran R, et al. 2002. P75 interacts with the Nogo receptor as a co-receptor for Nogo, MAG and OMgp. Nature, 420:74-8.

Wang KC, Koprivica V, Kim JA, et al. 2002. Oligodendrocyte-myelin glycoprotein is a Nogo receptor ligand that inhibits neurite outgrowth. Nature, 417:941-4.

Wehrle R, Camand E, Chedotal A, et al. 2005. Expression of netrin-1, slit-1 and slit-3 but not of slit-2 after cerebellar and spinal cord lesions. Eur J Neurosci, 22: 2134-44. 
Weidner N, Ner A, Salimi N, et al. 2001. Spontaneous corticospinal axonal plasticity and functional recovery after adult central nervous system injury. Proc Natl Acad Sci USA, 98:3513-18.

Wong ST, Henley JR, Kanning KC, et al. 2002. A p75(NTR) and Nogo receptor complex mediates repulsive signaling by myelin-associated glycoprotein. Nat Neurosci, 5:1302-8

Yamashita T, Higuchi H, Tohyama M. 2002. The p75 receptor transduces the signal from myelin-associated glycoprotein to Rho. J Cell Biol, 157:565-70.

Yamashita T, Tohyama M. 2003. The p75 receptor acts as a displacement factor that releases Rho from Rho-GDI. Nat Neurosci, 6:461-7.

Yamashita T, Fujitani M, Yamagishi S et al. 2005. Multiple signals regulate axon regeneration through the Nogo receptor complex. Mol Neurobiol, 32:105-11.

Yamashita T, Mueller BK, Hata K. 2007. Neogenin and repulsive guidance molecule signaling in the central nervous system. Curr Opin Neurobiol, 17:29-34.
Yokoyama N, Romero MI, Cowan CA, et al. 2001. Forward signaling mediated by ephrin-B3 prevents contralateral corticospinal axons from recrossing the spinal cord midline. Neuron, 29:85-97.

Yong VW, Wells J, Giuliani F, et al. 2004. The promise of minocycline in neurology. Lancet Neurol, 3:744-51.

Yune TY, Lee JY, Jung GY, et al. 2007. Minocycline alleviates death of oligodendrocytes by inhibiting pro-nerve growth factor production in microglia after spinal cord injury. J Neurosci, 27:7751-61.

Zheng B, Ho C, Li S, et al. 2003. Lack of enhanced spinal regeneration in Nogo-deficient mice. Neuron, 38:213-24.

Zheng B, Atwal J, Ho C, et al. 2005. Genetic deletion of the Nogo receptor does not reduce neurite inhibition in vitro or promote corticospinal tract regeneration in vivo. Proc Natl Acad Sci USA, 102:1205-10.

Zhou L, Baumgartner BJ, Hill-Felberg SJ, et al. 2003. Neurotrophin-3 expressed in situ induces axonal plasticity in the adult injured spinal cord. J Neurosci, 23:1424-31. 